\title{
The Influence of Parenting Style on Male Juvenile Delinquency: A Case of Kamiti Youth Correction and Training Center (KYCTC), Kiambu County, Kenya
}

\author{
Evans Onsando, Margaret K. Mwenje, and Perminus Githui
}

\begin{abstract}
The rising cases of delinquency among male teenagers is a feedback of sorts that the family system that is the nurturing context of children has failed to effectively protect the teenagers against negative influences. The scenario, has brought the nurturing role of parents into sharp focus. The purpose of this study was to establish the influence of the parenting styles on male juvenile delinquency at the Kamiti Youth Correction and Training Center (KYCTC), which is within Kiambu County, Kenya. The study was guided by Baumrind's parenting styles theory which categorizes parenting styles on the basis of responsiveness and demandingness in the parenting role. The study used purposive sampling method and simple random technique to select a sample of 68 males aged between 15 and 18 years from a target population of 120 delinquents at the KYCTC. The study used the ex post facto design. In this design data was collected through interviews, Focus Group Discussions (FGD) and self-administered questionnaire. Quantitative data collected through questionnaires was analyzed through descriptive statistics with the help of SPSS version 25.0 and qualitative data collected through in-depth interviews and focus group discussions was analyzed through thematic analysis. The findings of the study indicated that authoritarian parenting style $(42 \%)$ and permissive parenting style $(29.4 \%)$ posed the greatest danger to the development of juvenile delinquency. On the other hand, authoritative parenting style $(8.8 \%)$ posed the least danger to the development of juvenile delinquency. Presentation of data was done through tables, graphs and thematic descriptions of respondent's statements. The findings point to the critical role the parenting style plays in the development or prevention of juvenile delinquency. Strengthening of the parenting role, coordination with other key influencers including teachers, Government Departments such as the Children's Department and the Correctional Services, Rehabilitation Centers run by religious organizations and government rehabilitation programs such as KYCTC, can make a difference if each plays their critical role.
\end{abstract}

Index Terms — parenting style, juvenile, delinquency.

\section{INTRODUCTION}

A UN youth report (2003) painted a grim picture of juvenile delinquency in the world, indicating that in Western Europe, arrests of juvenile delinquents and under-age offenders increased by 50 per cent between the mid- 1980s and the late 1990s. United Nations Children's Fund (UNICEF), which is an affiliate of the United Nations, indicates that more than 1 million world's children are held in different prison facilities for delinquent behaviour [1].

Published on June 18, 2021

Evans Onsando, Pan Africa Christian University, Kenya.

(corresponding e-mail: evans.onsando @ ${ }^{\circledR}$ pacuniversity.ac.ke)

Margaret K. Mwenje, Pan Africa Christian University, Kenya.

(e-mail: margret.mwenje ${ }^{\circledR}$ pacuniversity.ac.ke)
Juvenile delinquency is considered to be among the most distressful problems among minors under the age of 18 years, which threatens positive development of moral, academic and social aspects of their lives. Elliott, Huizinga, and Menard [2], cite delinquent behavior to include disobedience to parents, drug and alcohol abuse, stealing, destruction of property and rape. There are varying views on the attributions of delinquent outcomes, but there is general consensus that it is largely manifested within the referred age bracket (adolescent years). In most jurisdictions, this is an age group that is still under the care of parents or responsible adults.

Delinquency is currently viewed as a social disease that cannot be treated effectively without first discovering its real causes. Shoemaker [3] describes delinquency as a variety of forms of antisocial behaviour consisting of illegal actions, in terms of violation of rules and criminal offenses, involving adolescents under the age of 18. On the other hand, Muhamad [4] gives delinquency a broader perspective by describing delinquents as children who are in conflict with societal norms and rules. Mental health practitioners view delinquency as a pattern of bad or disruptive behavior that can be attributed to the parenting role. In cases where the child is exposed to negative influences such as abuse, lack of affection and attention, the negative influences may first manifest in the child in the form of bulling and lying and may later degenerate to more serious anti-social activities, such as fighting and stealing [5].

A juvenile can be defined as a child who has not attained a certain age at which he, like an adult can be held liable for criminal acts, meaning that they are under the care of their parents. Bartollas [6] defines juvenile delinquency as acts that violate personal code as outlined by the government with authority in a given jurisdiction by a minor. However, Juvenile delinquency is deemed as such when the act would be deemed a crime if committed by an adult, the person charged is below the age outlined in law and the case is prosecuted in a Juvenile court.

Kenya's Children's Act [7] defines juvenile as a child under the age of 18 years, and who is in conflict with the law and is confined in a correctional institution. The age bracket is critical because any person below the age of 18 years is not considered an adult and therefore under the care of his parents or guardians. This is the reason why one cannot be issued with the Kenya national identity card because they are legally considered to be children.

Perminus Githui, Taita Taveta University, Kenya (e-mail: perminuskg@gmail.com) 
The underlying issue in the study was the antisocial behavior that teenagers develop and manifest in different social arenas. The society assigns the responsibility of inculcating socially desired behavior in families with the parents as the first respondents to this responsibility. Therefore, the prevalence of delinquent behavior has been attributed to parents' failure to properly nurture their children, thereby predisposing them to delinquent behavior that ultimately undermines the security of society as a whole. Bongaarts, Mensch and Blanc [8] argue that failure to come up with timely parental and familial intervention could snowball to undesirable juvenile behavior with far-reaching ramifications, such as serious bodily injury, arrest, or death, for both the parent and the teen. It is the considered view of the study, that adequate research in this area is required in order to establish the nexus between parenting practices and development of juvenile delinquency.

\section{PARenting Style And JuVEnile DelinQuency}

Parenting styles have been subjected to extensive research in recent years and have been associated with child outcomes and parental characteristics. Parenting styles can be broadly viewed as specific behaviors that parents deploy during their interaction with their children and the emotional environment created by parents as they raise their children [9]. Therefore, in the study, parenting was defined as practices and styles used by parents in the socialization of the children/youth. This socialization gradually shapes the moral behavior of the children that is ultimately manifested in the interaction with others in the society.

Parents play a key role in molding and shaping the behavior of children. Baumrind [10] came up with three parenting prototypes that describe patterns of parental interactions that include parental control and child socialization. Coste [11] cites the work of Baumrind, in identifying three parenting styles based on the domains of parental demandingness and responsiveness. He argues that juvenile delinquency is directly associated with the behavior parents adopt when they interact with their children. Authoritative parenting is associated with outcomes such as high levels of academic achievement, greater self-esteem and self-efficacy with minimal likelihood of bullying and other delinquent behaviors. Authoritarian parenting is on the other hand associated with depressive symptoms and rebellion against parents because of rules and strict disciplinary environment. Conversely, permissive parenting style is linked to youth who turn out to be bullies, manipulators and defiant because they are used to getting whatever they wanted from their parents. Though not directly linked to Baumrind, a fourth classification called uninvolved or neglectful parents' style is linked to low levels of academic achievement, aggressive, disruptive, and non-cooperative behavior that often manifests emotional problems, such as depression and suicide ideation because there was no parental guidance to them [12].

Many parents are apparently ignorant of the fact that their strict tendencies may turn out to be counterproductive and are pushing the children away from them to peers, which inadvertently exposes them to delinquency. This study sought to frame the parenting practices into parenting styles that affect the development of juvenile delinquency.

A study in Nigeria that targeted secondary school children found that lack of parental monitoring contributed to the development of anti-social behaviors, besides exposing them deviant peers, which is predictive of higher levels of deviant acts [9].

The parenting relationship is, therefore, the launch pad and the lenses through which, children/adolescents view the world. This is the first learning institution where the belief system and values are formed. Parents, therefore, bear the greatest responsibility of molding and influencing the future behavior of their children through the parenting style they adopt. It is important to note that children are born helpless and totally dependent on their parents for nurture and care until such a time that they are self-sustaining [13].

Parents provide children with the framework from which they can begin to develop and cultivate their own value system. This framework is developed through socialization,

observation and interactions that children have with their parents [14]. Scalici and Schulz [15] point out that a child's development begins and progresses through interactions with parents and other family members. Parental influences are deemed to be strongest during childhood and compared to when the child grows older. Therefore, inadequate parental supervision is one of the major reasons for development of delinquent behavior. The process of the transmission of values from parents to children begins at a young age and can have lasting effects on the future of individuals as well as socialization for generations to come. Therefore, the deployment of a more responsive parenting style determines the value system adopted by the child as they grow into adulthood.

Altan-Aytun et al. [16] identified parent-child interactional patterns including communication, decision making, emotional conversations, and affective involvement in family relations that could be used to identify parenting styles or patterns of behaviors. They further argue that the above aspects determine the levels of functioning of families.

Other studies have confirmed that the quality parent-child relationship is a major influencer of the development of the child's future belief system or morality [17]. The style of parenting can influence the general development of the child in three ways; first, the parents model societal norms as they relate with the child hence influences the child to adopt to the standards, second, the child is taught how to regulate their emotions which assists the child in relating with others and complying with rules and regulations and third the child will learn the principle of give and take due to the reciprocal relationship exhibited in a secure attachment relationship. [18]. The influential role that parents play during their interaction with their children was a subject of interest in the study since these interactions have a direct bearing on delinquency of the child.

Gauvain, Perez, and Beebe [19] point out that critical information about the dominant parenting style deployed by respective parents can be identified through the parent's response to their children's emotions, how they manage their own emotions, and the affective environment created in the cycle of their interactions. Conversely, important information on the overall parenting style can also be found through assessment of the family functioning and patterns of 
interaction within the family.

Baumrind [20] and Steinberg [21] point out that there is a convergence of evidence from longitudinal studies that claim that parenting styles account for about 30 percent of youth delinquency and in cases where other variables are leading to delinquency, authoritative parenting style may mediate the effects.

Authoritative parenting style offers guidance and direction in a rational manner. The level of demandingness and responsiveness in this style is higher meaning that parents' welcome open communication and encourage a strong relationship [22]. Hoskins [23] adds that authoritative parenting exhibits more support towards children. The parents engage in a give-and-take kind of conversation, explains the rationale behind existing rules and regulations. Authoritative parenting is closely linked to positive adolescent outcomes such as assertive and self-reliant behavior. In other words, authoritative parenting style inculcates positive attributes including compliance with social norms among adolescents.

Authoritative parents are considered the ideal models for effective child social development and education because the parents offer a balanced menu of affection and support on one hand and constructive/flexible disciplinary arrangement on the other [24]. The importance of striking a balance between warmth and boundaries is a challenge to many parents. Manifestation of warmth and boundaries are important domains in the current study since they determine the kind of parenting style adopted by the parent.

Georgiou, Ioannou and Stavrinides [25] conducted studies on authoritative parents and established that they deployed a balanced form of demandingness and responsiveness through. effective communication with their children, liberally praised their children and readily disciplined their children when they violated boundaries. They associated authoritative parenting with a healthy self-esteem, high levels of academic achievement and self-efficacy and lower likelihood of delinquent behavior. Authoritative parenting has been identified as one of the key protective measures against delinquency.

Hoskins [23] argues that families that have cultivated a strong parental relationship with their children normally succeed to minimize the risk of delinquency in their children when they become adolescents. He attributes this to the fact that the established bond with the family tends to obligate them to care more about their parents' expectations thereby deterring them from delinquent behavior. This study sought to explore how parenting style based on responsiveness and demandingness determines the development of juvenile delinquency. Baumrind [26] underscores the fact that authoritative parents manifest their responsiveness by exhibiting appropriate warmth and affection on one hand and readily confront their children on the other, thus demonstrating a broad spectrum of adaptive emotions.

Authoritarian style parenting is characterized by low response to the child's requirements and placing high demands on children leading to general discontent and withdrawn child behavior. The parents deploying this style are known to stress issues such as strict adherence to the rules and thus demand to be obeyed without explanation. They tend to use power, prohibition, and punishment to control and achieve obedience. This type of parenting has been linked to various negative effects on child mental health, including depressive symptoms [27]. This parenting style deploys low levels of interactions and trust towards their children. They often avoid open communication and place strict control over their children. The authoritarian parenting style is generally forceful, punitive and believes that a child should always stick to procedure. Nijhof and Engels [28], associate authoritarian parenting to lower levels of ability and selfconfidence.

Authoritarian parents display very rigid discipline, minimal flexibility, and demands for adherence of rules and regulations in the family set up. The parents are very controlling on one hand and not receptive to the child's needs or requests [24], [29]. This parenting style inhibits the child's personal development and independence. In their bid to get their freedom, the child is more likely to rebel by turning to delinquency. Baumrind [30] summarizes her description of authoritarian parenting as marked by less warmth than authoritative parents, rejecting and psychologically controlling. Authoritarian parenting has been linked to child's inadequate behavioural tendencies because of the parent's uncompromising demands for strict obedience and adherence to a preconceived code of conduct marked by forceful and undemocratic tendencies.

The use of this kind of parenting style exerts a lot of pressure on youth to a point that they cannot easily communicate their issues with parents, consequently drifting to peers for support and comfort. The drifting of the child from the parents care to peers may turn out to be a precursor for juvenile delinquency.

Permissive style of parenting is characterized with high responsiveness to the needs and wants of a child and low demands in as far as adherence to rules are concerned. Parents using the permissive style are normally very supportive, easily make time for their children, and are generally lenient. Whereas these attributes manifest high responsiveness, they often fail to establish boundaries and when they do, they do not enforce them [24]. Permissive parents are usually described as loving, non-punitive and accepting since they set few rules and boundaries for conduct, thus stressing freedom more than responsibility. Children from permissive parents normally score lower academic grades and are more likely to be engaged in bullying of others [31]. Youths with permissive parents have problems adjusting to societal realities. When parents fail to monitor, control, and even punish children for deviant behavior or disobedience, the effect on the youth is lack of self-control, which increases the risk of delinquency. Church et al. [12] aver that children, who grow up with lack or lax family rules, parental monitoring and no curfew expectations, are at a greater risk to be engaged in high levels of delinquency. Such children manifest low self-control and low self-reliance.

Baumrind [26] describe permissive parents as those who promote psychological freedom, are accommodating, and are not keen on erecting boundaries around their children. Other than their tendency to encourage their children and failure to monitor them, they generally shun situations that place them in a collision course with their children considering to be rather generous and having their children freely make their own decisions. Children nurtured by permissive parents end 
up attaining inadequate [32], no self-control [33], and lack of independence.

This parenting style leads to youth who have problems living or working in environments where there are strict rules. They will therefore find themselves in trouble with the law or regulations of organizations frequently. This will, therefore, affect their self-esteem. Therefore, the present study will seek to identify parenting styles that will positively influence the development of youth and prevent them from indulging in juvenile delinquency.

The rejecting/neglecting parenting style, scores low on both responsiveness and demandingness yielding children who are indecisive and carefree. Neglectful parenting exposes youth to lack adult supervision making them to parent themselves thus assuming parental role to younger siblings. The parents in essence disconnect themselves emotionally from their children and provide no boundaries to the children at all. Other studies have classified neglectful parenting as a critical enabler to the children in the access to weapons, drugs, rape, prostitution, pornography, and violent gang activity. Calafat [31] describes neglectful parents as those who offer little or no supervision, do not set boundaries and show little or no affection and support. The study revealed that minors of neglectful parents perform poorly academically, are aggressive, uncooperative, disruptive, and prone to emotional problems such as depression and suicide ideation. Among all parenting styles, this one portends the greatest risk to youths getting involved in delinquency [34]. Some parents may continue abdicating their role in pursuit for other things which directly pushes the children to delinquency.

Baumrind [30] describes neglectful parents as rejecting and lax behavioral control. These parents minimize parenting effort and time while manifesting aggression or indifference and failing to attend to the child's needs.

Among the four parenting styles, there is general consensus that authoritative parents are considered the ideal models for effective child social development and education because the parents offer a balanced menu of love, care, affection and support on one hand and constructive/flexible boundaries and disciplinary arrangement on the other. This bidirectional approach that involves response to the youth's need and reasonable rules governing the youth's conduct engenders self-control and minimizes the risk of minors being involved in delinquent behavior [24].

On the other hand, permissive and neglectful parenting styles have been identified to pose the greatest risk for development of juvenile delinquency. Due to the failure of permissive parents to monitor their children and their excess levels of conceding to the child's demands, their children's manifest levels of delinquent behavior [20]. Minors from permissive family systems are prone to school misconduct, substance use, and are faced with interpersonal challenges among their peers. Notably, the children also have low selfesteem [35].

Conversely, neglectful/uninvolved parenting style, which is marked by failure to engage in structure or control of the children and a lack of closeness in the parent-child dyad creates a favourable environment for externalizing behaviors of children [36]. Martínez, and García [35] have linked uninvolved parenting style to delinquent acts among them rape, theft, vandalism, and assault. Other studies established that adolescents from neglectful families drank alcohol and abused other substances almost twice as much as their peers that from other parenting styles families [36].

Tompsett and Toro [37] point out that the risk of development of delinquent behaviour among adolescents is often linked to parenting style. They specify Authoritarian parental style particularly as influential in developing delinquent behavior among adolescents.

Based on the cited literature, parenting style is an integral part of the socialization of a child. Most parenting practices are learnt through observation and modeling of older parents. Some of the practices adopted are to blame for the rising cases of juvenile delinquency. There is dire need for a shift of the practices to styles that positively influence children.

\section{THEORETICAL FRAMEWORK}

Baumrind's parenting styles theory is one of the most elaborate theories that is credited for categorization of parenting practices with predicted outcomes on children and youth.

This theory is based on three studies carried out in the 1960s and 1970s by Diana Baumrind. In the studies she selected different samples of pre-school children who exhibited different behaviors, with the help of teachers and psychologists. The behaviors that Baumrind was interested in were: (1) Assertive, self-reliant, self-controlled, buoyant, and affiliative, (2) discontented, withdrawn, and distrustful and (3) little self-control or self-reliance and retreat from novelty [38].

Through laboratory observations, home observations and parent interviews, the studies identified three parenting styles that were related to patterns of child behavior. Baumrind used two dimensions in the categorization of parenting styles. The dimensions were based on the relational patterns of values (high or low) of the responsiveness (warmth) and demandingness (control) dimensions of parenting. The three parenting styles, as argued later by Maccoby and Martin [33] were identified as authoritative style (characterized by high levels of both responsiveness and demandingness), which was associated with assertive, self-reliant child behavior; the authoritarian style (low responsiveness and high demandingness) was linked to discontented and withdrawn child behavior; and permissive style (characterized by high responsiveness and low demandingness) was associated with low self-control and low self-reliance of children. From further studies, there emerged a fourth parenting style called neglectful/uninvolved that was marked by low responsiveness and demandingness. Children who were born of neglectful parents exhibit aggressive, disruptive, and noncooperative behavior.

She points out that responsiveness can be measured in terms of the level of reciprocity, warmth and communication exhibited by parents as they interact with adolescents. Based on this argument, parents who show high levels of rewarding good conduct, affection and open communication are considered to be highly responsive.

Conversely, demandingness can be described as expectations, disciplinary efforts, supervision, and willingness to confront a disruptive child. Simons, Simons, 
and Wallace [39] posit that demandingness can be measured through "well-defined monitoring techniques, direct confrontation and discipline patterns utilized by parents". Based on this argument, parents with higher levels of discipline patterns, confrontation and monitoring are deemed demanding, whereas parents with lower level of confrontation, inconsistent discipline and monitoring are described as not demanding

Later studies by Cherry [40] came up with four imperative domains of parenting out of Baumrind's two domains (responsiveness and demandingness) to include: communication styles, nurturance and warmth, expectations of adulthood and control, and disciplinary strategies. These domains were used to come up with four parenting styles: authoritative, authoritarian, permissive and neglectful style. Baumrind [30] broadened the dimension of responsiveness to also include parental acceptance, attunement to the child's needs, support, and warmth. These domains were used in this study as well.

On the other hand, Baumrind described demandingness as control measures or manifestation of family authority. However, Baumrind [26] argued that demandingness must be viewed as qualitatively different when considering different parenting styles and these differences must be clarified. Demandingness deployed by authoritative parents is referred to as reasonable control, marked by firm and 'hands on', monitoring generally referred to as conduct control. This type of demandingness has been associated with positive outcomes for children. Confrontive behavioral control is considerate and reasonable. Conversely, demandingness deployed by authoritarian parents is called coercive control, which is marked by a damaging mode of power display that is invasive, cruel, and vindictive and has been related to negative child behaviour. Authoritarian parents exercise psychological control as opposed to psychological autonomy. This control undermines a child's sense of being due to its overly controlling nature. It is also marked by coercion, manipulation, conditional regard, and disrespect [30].

Generally, this theory views parenting as an interactional pattern adopted by a parent in the care, raising, and education of a child. Key to this pattern is the attachment and caregiving systems that are normally activated simultaneously as the parents continuously interacts with their children in the process of meeting their physical, emotional, and psychological needs [20].

In as far as this theory is concerned, there is a high likelihood of delinquency in cases where a minor's emotional bond with significant others especially parents is weak or diminished. In the absence of this bond, the child is more vulnerable to establish alternative bonds to fill the void and is therefore more inclined to adopt unconventional norm that will put the child at cross fires with the law [41]. Parenting styles theory has been a subject of many studies that have sought to establish the relationship between parenting styles and different aspects of child outcomes. Most of the studies have found that authoritative parenting is associated with positive development outcomes such as emotional stability, adaptive patterns of coping and life satisfaction. Baumrind [26] identifies authoritative parenting as the appropriate model since the parents are more responsive to the needs of the children and are also ready to erect boundaries around the children's activities. Authoritative parents are considered reasonable, warm, considerate, and supervises their children in more appropriate ways. Conversely, Maccoby and Martin [33] depicts parents who use this model as parents who set clear rules and are reasonable when enforcing them, they encourage open communication, support their children's freedom, and warmly interacts with them. Authoritative parenting style has been distinguished as the appropriate parenting model and is associated with positive aspects including self-reliance, social responsibility, and adjustment [30], [33].

Authoritarian parenting style was linked to poor academic achievement and depressive symptoms while permissive and neglectful styles of parenting are associated with aggression, low self-esteem and poor self-control [42].

Parenting styles theory was deemed appropriate for the study since it provides the major domains that will be used in the measurement of the types of parenting styles used in the nurture of the delinquents. The styles can also be easily associated with children's outcomes that make them susceptible to juvenile delinquency. These features make the theory appropriate for the study. However, the theory does not cater for the family structure that is an important variable for the present study.

\section{RESEARCH METHODOLOGY}

The present study will adopt the ex post facto design using both quantitative and qualitative data collection methods This design is appropriate because it helps to investigate possible causes of an existing condition or state of affairs and searching back in time what could have contributed to the condition. This design is non- experimental but adopts several aspects of an experiment since it deals with separation of groups and the analysis of data. It is appropriate in making comparisons between individuals who belong to different groups but have identical backgrounds. In this study the identical background of respondents is that they are all delinquent. However, in this design, the researcher does not have control over the independent variable. In the study the independent variables drawn from the family system were the parenting styles adopted by the parents of the juveniles and the family structure that they belong to. These variables were beyond the control of the researcher.

The target population was juveniles below the age of 18 years held at the KYCTC. A sample of 68 juveniles was drawn from a population of 120 using random sampling method for the study.

In the study, the focus was on how the parenting style influences the development of juvenile delinquency. The ex post facto design was considered appropriate for the study since the respondents were all held in a correctional facility due to their involvement in delinquent activities. The independent variable that has an effect on juvenile delinquency was parenting styles.

The study focused on male juveniles involved in antisocial behavior under the custody of the Kenya prison warders. The independent variable was outside the researchers' control thus appropriate to study its influence on the dependent variable. 
The targeted population and age bracket were relevant to the study since they are all convicted of juvenile delinquency related offences and therefore have the relevant information that was required for the study to meet the objectives.

KYCTC normally holds between 220 and 300 juveniles at any time according to Prison Authorities. However, due to the COVID-19 pandemic the number had been reduced to about 120. The sample size for the study was based on a criterion outlined by Mugenda and Mugenda [43], who argue that when the study population does not exceed 10,000, a sample size of between 10 and $30 \%$ is a good representation of the target population. The study targeted a sample of 68 juveniles who made up $56 \%$ of the population.

In order to collect data sufficient for the study, the following data collection tools were used: questionnaires, interview schedule and unstructured interview guides. These tools were used to collect relevant information in relation to the objective of the study. All the tools for the study were written in English. In cases where the respondents did not understand English, a translator among the prison officials was sought to assist the respondents.

The questionnaires were administered to the respondents in the sample with the help of research assistants within the correctional services. The questionnaire had three parts covering, general demographics, family structure/environment of parenting and parenting styles. The questionnaire had 20 statements that identify three parenting styles based on Baumrind's parenting styles. The statements measured two critical dimensions of Baumrind's parenting styles namely, demandingness and responsiveness. Responsiveness was measured in terms of the level of reciprocity, warmth and communication exhibited by parents as they interacted with adolescents while demandingness was measured in terms of well-defined monitoring techniques, direct confrontation and discipline patterns utilized by parents.

Focus Group Discussions: The tool was applicable to the study and was appropriate for collecting qualitative data. The FGDs offered an in-depth discussion on thematic areas of the study that would not be available through surveys. The tool targeted six groups of eight respondents each with the researcher being the moderator. The discussions sought to establish the respondent's perceptions attitudes, beliefs, opinion, or ideas. During the discussions, the participants were encouraged to not only express their own opinions, but also respond to other members and questions posed by the leader.

Their contributions were written verbatim and were recorded for accuracy of the responses. The goal of the faceto-face interviews was to capture the experiences, beliefs, interpretations and attitude of the respondents on the thematic areas of the study. The interviews were conducted at the KYCTC.

Quantitative data collected through questionnaires was sorted, classified, coded, and entered and analyzed with the help of SPSS version 25.0. Quantitative data was categorized and coded in order to generate frequencies and percentages. The percentages and frequencies were presented in form of tables, bar graphs and pie charts that facilitated drawing of connections and conclusions. On the other hand, qualitative data was analyzed using thematic descriptions. Analysis was done based on a pre-defined framework derived from the research questions. This process was preceded by a thorough review of the in-depth interviews and focus group discussions that led to data transcription, coding, sorting and categorization. The spoken word, continuity and inconsistencies of opinions, frequency and strength of remarks, their specificity, as well as emerging themes and trends, all received special attention. This process facilitated drawing of conclusions.

\section{FINDINGS OF THE STUDY}

The findings of the study are summarized in the table below.

\begin{tabular}{|c|c|c|c|c|c|}
\hline S/No & Parenting Style & Frequency & Percent & $\begin{array}{c}\text { Valid } \\
\text { Percent }\end{array}$ & $\begin{array}{c}\text { Cumulative } \\
\text { Percent }\end{array}$ \\
\hline 1. & Authoritarian & 29 & $42.6 \%$ & $42.6 \%$ & $42.6 \%$ \\
\hline 2. & Authoritative & 6 & $8.8 \%$ & $8.8 \%$ & $8.8 \%$ \\
\hline 3. & Permissive & 20 & $29.4 \%$ & $29.4 \%$ & $29.4 \%$ \\
\hline \multirow[t]{2}{*}{4.} & Undifferentiated & 13 & $19.1 \%$ & $19.1 \%$ & $99.9 \%$ \\
\hline & Total & 68 & $99.9 \%$ & $99.9 \%$ & \\
\hline
\end{tabular}

The objective of the study was to identify parenting styles associated with juvenile delinquency. The findings of the current study established that authoritarian parenting style was more common among parents whose children end up developing juvenile delinquency with $42.9 \%$ (29) followed by permissive parenting style with $29.4 \%$ (20) clearly demonstrating that these styles are more prone to breeding delinquents. On the other hand, authoritative parenting styles appeared to pose the least risk to development of juvenile delinquency at $6(8.8 \%)$.

The findings on this objective have clearly established that there is an association between parenting styles and the development of Juvenile delinquency. The style of parenting can influence the general development of the child in three ways; first, the parents model societal norms as they relate with the child hence influences the child to adopt to the standards, second, the child is taught how to regulate their emotions which assists the child in relating with others and complying with rules and regulations and third the child will learn the principle of give and take due to the reciprocal relationship exhibited in a secure attachment relationship. [18].

These findings tend to disagree with the notion that authoritative parenting produces positive results in Europe and not Asia and Africa where the dominant parenting practice is authoritarian. On the contrary, authoritarian parenting tends to be the main contributor to the development of juvenile delinquency. This position is supported by a study by Smetana and Ahmad [44] who found that authoritarian parenting (yelling, shaming, corporal punishment) predisposes an adolescence to embrace delinquency across cultures.

The findings are similar to studies carried out by Tompsett and Toro [37] who found out that the risk of development of delinquent behaviour among adolescents is often linked to parenting style. They specified authoritarian parental style particularly as influential in developing delinquent behavior among adolescents due to the non-responsive approach of the 
style. The parents deploying this style are known to stress issues such as strict adherence to the rules and thus demand to be obeyed without explanation. They tend to use power, prohibition, and punishment to control and achieve obedience. This type of parenting has been linked to various negative effects on child mental health, including depressive symptoms [27].

The findings on authoritative parenting style are confirmed by results of a study conducted by Hoskins [23] who concluded that authoritative parenting exhibits more support towards children and offers guidance and direction in a rational manner. The level of demandingness and responsiveness in this style is higher meaning that parents' welcome open communication and encourage a strong relationship [22]. Conversely, authoritative parents are considered the ideal models for effective child social development and education because the parents offer a balanced menu of affection and support on one hand and constructive/flexible disciplinary arrangement on the other [24].

The findings are also in agreement with a study conducted by Calafat [31] that classified permissive parenting as a critical enabler to the children in the access to weapons, drugs, rape, prostitution, pornography, and violent gang activity. The same study describes permissive parents as those who offer little or no supervision, do not set boundaries and show little or no affection and support. The study revealed that minors of permissive parents perform poorly academically, are aggressive, uncooperative, disruptive, and prone to emotional problems such as depression and suicide ideation [34].

Church et al. [12] agree with the above findings stressing that children, who grow up with lack or lax family rules, parental monitoring, and no curfew expectations, are at a greater risk to be engaged in high levels of delinquency. Such children manifest low self-control and low self-reliance. This parenting style leads to youth who have problems living or working in environments where there are strict rules. They will therefore find themselves in trouble with the law or regulations of organizations frequently. This will, therefore, affect their self-esteem.

\section{A. Focus Group Discussion}

During the focus group discussions interesting remarks were made that clearly indicated the parenting style adopted by the parents or guardians. Some of the statement made are as follows:

"I joined a group of teenagers who taught me how to steal. I often left home early in the morning pretending that I was going to school just to team up with the teenagers. I remember not coming home for two days and my parent did not ask me where I was after returning home with some stolen items".

This remark paints a picture of a parent who abdicates his/her role of guiding a child. The child is gradually subjected to the influence of peers who turn out to be a moral compass for the child because the parents are virtually absent for the child. The void created by the absent parent is filled by peers who introduce the child to delinquency. This statement bears the hallmarks of a permissive parent who does not bother to sanction or punish the child while allowing the child to make most of the decisions themselves. This posture is dangerous to the children.

Another Juvenile narrated his experience at home:

"My mother often came home, angry and blamed me for the disorganization in the house and would mercilessly beat me up and deny me food that evening. She was often moody and constantly in arguments with the neighbours. I felt like a prisoner in that home. Any requests I made were responded to in terms of scolds and blows. I had no choice but to run away from home".

This response was shared by five out of the six focus groups. The physical and verbal abuse of the teenagers only serves to build resentment in their lives. The tendency to physically punish a child without explanation are marks of authoritarian parenting which eventually pushes the child away from the parent, this explains why most of the juveniles had parents who were authoritarian in their parenting model which pushes the children away from the parents to delinquency. This is an indication that the parenting style and family structure can influence juvenile delinquency.

Another Juvenile revealed that:

"We never knew what our parents did for a living. They would come home in different times of the night and go straight to bed. They never looked at our school diary. At times our father would disappear for months and later reemerge. We were complete strangers with our father since he never played with us or give us and form of guidance".

This is a case of parents who display low responsiveness and low demandingness which can be classified as neglectful and yet they live in the same house. The children in this situation manage their own lives and end up in problems. Supervision and guidance from parents are lacking thus pushing them to delinquency.

From the responses it is clear that most parents failed to monitor and supervise their children indirectly pushing them to the hands of peers who are also inexperienced. Another key feature that manifested itself is the tendency of parents becoming abusive to their children through assaulting them. Other parents did not take time to do their roles of providing for the basic needs for their children. The remarks are indicative of the type of parenting style adopted by the parents. Common types among the juveniles at KYCTC are authoritarian marked by many sanctions without providing for the needs of the juvenile and permissive style identified by parents allowing their teenagers to make their own decision without referring to them and failure to follow up on important issues such as school progress.

\section{CONCLUSION}

The current study focused on the influence of parenting style on the development of juvenile delinquency. Based on the findings of this study, it is clear that the parenting practices adopted by parents have a big influence in the development of delinquency among teenagers. As cited in this study, a child at the point of birth is helpless and completely dependent on the parent for nurture. The question of how the children turnout when they mature, is squarely in the province of parents and society. The study has established that authoritative parenting style which is marked by warmth and care on one side and supervision and monitoring on the other is the most appropriate style that acts as a buffer that 
would ultimately prevent the children from slipping into juvenile delinquency.

All parents nurturing children and adolescents should strike a balance of responsiveness where they deliberately show warmth, open lines of communication, involve children in decision making and explains reasons for some sanctions on one part and on the other exercise behavioural control that is both considerate and reasonable.

\section{RECOMMENDATIONS}

Based on the findings of this study, the following recommendations if implemented and sustained would probably make a positive impact on the problem of juvenile delinquency.

1) Parental training programs need to be mounted with a view to enhancing parents' ability to monitor their children's activities, reinforcement of good behavior, clearly state rules, and expectations for behavior. Other than this posture, the parents need to be trained on how to build stronger emotional bonds with children and adequately respond to their needs. This will restore parental power which has been ceded to other teenagers or even relatives in the passage of time.

2) At the individual level, to prevent teenagers from falling into bad company, it is recommended that they be offered assertive trainings to assist them make decisions that are good and appropriate for themselves. Assertiveness empowers the teenager to say 'no' to antisocial behavior and to have the strength to walk away from a group that has negative influence.

3) At the community level, local communities should be encouraged to be actively involved in stemming delinquency in their local areas through initiatives such as mentorship programs and sensitization programs highlighting the negative effects of delinquency.

4) A deliberate collaboration between school and family will go a long way in detection and interdiction of juvenile delinquency. The role of the school should not be limited to impartation of knowledge but also inculcation of morals in conjunction with the family or guardians. Establishment of policy supported structure of engagement between the schoolteachers and family would assist in identification of pupils who fail to go to school without the knowledge of the parents.

5) The government should come up with policies that would compel parents to attend forums that are related to their children's activities such as school events and other forums organized by the government.

\section{REFERENCES}

[1] Bochenek, M. G. (2016). Children Behind Bars. World Report 2016. Human Right Watch. Retrieved from: https://www.hrw.org/worldreport/ 2016/children-behind-bars.

[2] Elliott, D. S., Huizinga, D., \& Menard, S. (2012). Multiple problem youth: Delinquency, substance use, and mental health problems. New York: Springer.

[3] Shoemaker, D.J. (2010), Theories of Delinquency, an Examination of Explanations of Delinquent Behaviour New York, USA: Oxford University Press.

[4] Muhamad, M. (2007). Teacher's handbook for exceptional children. United Kingdom: Anmol.
[5] Kariuki, S.N (2014). Relationship between Adolescents' Perceptions of Their Parents' Behaviors and the Teenagers' Non- Illegal and MinorIllegal Delinquency in Nairobi Secondary Schools, Kenya. Retrieved from library. ku.ac.ke/handle/123456789/155/browse?rpp=20\&order.

[6] Bartollas, Clemens, Frank Schmalleger, and Michael Turner. (2014) Juvenile Delinquency. New York. Pearson Education Inc., 2019.

[7] Children's Act (2001). Definition of Juvenile.

[8] Bongaarts, J., B. Mensch and A. Blanc (2017), "Trends in the age at reproductive transitions in the developing world: The role of education", Population Studies, Vol. 71/2, pp. 139-154Bowlby, J. (1969) Attachment and Loss: Vol. 1. Attachment. Basic Books, New York, NY, USA.

[9] Okorodudu, G. (2010). Influence of parenting styles on adult delinquency in Delta Central Senatorial District. Edo Journal of Counseling, 3(1) 58-86.

[10] Baumrind, D. (1966, 1968). Effects of authoritative parental control on child behavior. Child Development, 37(4), 887-907.

[11] Coste, B. (2015). Positive parenting: Practicle advice and deep insights. Retrieved from http://www.positive-parenting-ally. com/3-parentingstyles.htmlShoemaker, D. J. (2010). Theories of delinquency an examination of explanations of delinquent behavior (6th Ed.). United States of America, USA: Oxford University Press.

[12] Church, W., Jaggers, J., Tomek, S., Bolland, A. C., Bolland, K. A., Hooper, L., \& Bolland, J. M. (2015). Does permissive parenting relate to levels of delinquency? An examination of family management practices in low income black families. Journal of Juvenile Justice, 4(2), 95-110.

[13] Johnson, S. (2013). Love Sense: The Revolutionary New Science of Romantic Relationships. Little Brown Spark: New York.

[14] Bandura, A. (1971). Adolescent Aggression. New York: Ronald Press

[15] Scalici, F., \& Schulz, P. J. (2014). Influence of perceived parent and peer endorsement on adolescent smoking intentions: Parents have more say, but their influence wanes as kids get older. PLoS One, 9, e101275. doi:10.1371/journal.pone.0101275.

[16] Altan-Aytun, O., Ygmurlu, B., \& Yavuz, H. M. (2013). Turkish mothers'coping with children's negative emotions: A brief report. Journal of Child and Family Studies, 22, 437-443.

[17] Kochanska, G., Aksan, N. \& Carlson, J. J. (2005) Temperament, relationships, and young children's receptive cooperation with their parents. Developmental Psychology, 41, 648-660.

[18] Grusec, J. E. \& Davidov, M. (2010) Integrating different perspectives on socialization theory and research: a domain-specific approach. Child Development, 81, 687-609.

[19] Gauvain, M., Perez, S. M., \& Beebe, H. (2013). Authoritative parenting and parental support for children's cognitive development. In R. E. Larzelere, A. S. Morris, \& A. W. Harrist (Eds.) Authoritative parenting: Synthesizing nurturance and discipline for optimal child development (pp. 211-233). Washington, DC: American Psychological Association Press. doi:10.1037/13948-010.

[20] Baumrind, D. (1996). Parenting styles and adolescent development. In the Encyclopedia on Adolescence; bBrooks-Gunn, J., Lerner, R., Petersen, A.C., Eds.; Garland Publisher: New York, NY, USA.

[21] Steinberg L (2001) We know some things: Adolescent-parent relationships in retrospect and prospect. Journal of Research on Adolescence 11(1): 1-20

[22] Piko, B. F., \& Balázs, M. Á. (2012). Authoritative parenting style and adolescent smoking and drinking. Addictive Behaviors, 37(3), 353356.

[23] Hoskins, D. H. (2014). Consequences of parenting on adolescent outcomes. Societies, 4(3), 506-531.

[24] Trinkner, R., Cohn, E. S., Rebellon, C. J., \& Van Gundy, K. (2012). Don't trust anyone over 30: Parental legitimacy as a mediator between parenting style and changes in delinquent behavior overtime. Journal of Adolescence, 35, 119-132.

[25] Georgiou, S., M. Ioannou and P. Stavrinides (2017), "Parenting styles and bullying at school: The mediating role of locus of control", International Journal of School \& Educational Psychology, Vol. 5/4, pp. 226-242.

[26] Baumrind, D. (2012). Differentiating between confrontive and coercive kinds of parental power-assertive disciplinary practices. Human Development, 55, 35-51. doi: 10.1159/000337962.

[27] King, K., R. Vidourek and A. Merianos (2016), "Authoritarian parenting and youth depression: Results from a national study", Journal of Prevention \& Intervention in the Community, Vol. 44/2, pp. 130139.

[28] Nijhof, K. S., C., R., \& Engels, M. E. (2007). Parenting styles, coping strategies and the expression of homesickness. Journal of Adolescence, 30(5), 709-720.

[29] Laurson, B., \& Collins, W. A. (2009). "Parent-Child Relationships during Adolescence". In R. Lerner \& L. Steinberg (Eds) Handbook of 
Adolescent Psychology, 3rd Ed. (pp. 3-42) Hoboken, NJ, Wiley \& Sons.

[30] Baumrind, D. (2013). Authoritative parenting revisited: History and current status. In R. E. Larzelere, A. S. Morris, \& A. W. Harrist (Eds.) Authoritative parenting: Synthesizing nurturance and discipline for optimal child development (pp. 11-34). Washington, DC: American Psychological Association Press. doi:10.1037/13948- 002/.

[31] Calafat, A. (2014), "Which parenting style is more protective against adolescent substance use? Evidence within the European context." Drug \& Alcohol Dependence, Vol. 138, pp. 185-192.

[32] Baumrind,. D. (1971).Current patterns of parental authority. Developmental Psychological Monographs, 4 No. 1, Part 3.

[33] Maccoby E., \& Martin J. (1983). Socialization in the context of the family: Parent-child interaction. In: Mussen PH (ed), Handbook of Child Psychology. Wiley: New York;1-101.

[34] Hoeve, M., Stams, G. J. J. M., van der Put, C. E., Dubas, J. S., van der Laan, P. H., \& Gerris, J. R. M. (2012). A meta-analysis of attachment to parents and delinquency. Journal of Abnormal Child Psychology, 40, 771- 785.

[35] Martínez, I. \& García, J.F. (2007). Impact of parenting styles on adolescents' self-esteem and internalization of values in Spain. Span. J. Psychol., 10, 338-348.

[36] Garcia, F., Serra, E., Garcia, F.O., Martinez, I. \& Cruise, E.(2019). A Third emerging stage for the current digital society? Optimal parenting styles in Spain, the United States, Germany, and Brazil. Int. J. Environ. Res. Public Health, 16, 2333.

[37] Tompsett, C. J., \& Toro, P. A. (2010). Predicting overt and covert antisocial behaviors: parents, peers, and homelessness. Journal of Community Psychology, 38(4), 469-485.

[38] Baumrind, D. (1967). Child care practices anteceding three patterns of preschool behavior. Genetic Psychology Monographs.

[39] Simons, R. L., Simons, L. G., \& Wallace, L. E. (2004). Families, delinquency, and crime: Linking society's most basic institution to antisocial behavior. Los Angeles: Roxbury Publishing Company.

[40] Cherry, K. (2015). Parenting styles: What they are and why they matters. Retrieved from http://psychology.about.com/ od/developmental psychology/a/parenting-style.htm.

[41] Godinet, T.M. and Vakalahi, O.H. (2009). Conceptualizing Delinquency among Samoans Adolescents: An Integrative Model. Journal of Ethnicity in Criminal Justice , 7, 135-159.

[42] Low S, Snyder J., \& Shortt J.W. (2012). The drift toward problem behavior during the transition to adolescence: The contributions of youth disclosure, parenting, and older siblings. J Res Adolescence;22: 65-79.

[43] Mugenda, O. M., \& Mugenda, A. G. (2012). Research Methods: Quantitative and Qualitative Approaches. Nairobi: Acts Press.

[44] Smetana, J.G., \& Ahmad, I. (2018). Heterogeneity in perceptions of parenting among Arab refugee adolescents in Jordan. Child Development, 89, 1786-1802. 